\title{
Improvement of Mechanical, Thermal, and Morphological Properties of Organo- Precipitated Calcium Carbonate Filled LLDPE/Cyclic Natural Rubber Composites
}

\author{
Ahmad Hafizullah Ritonga ${ }^{1,2}$, Novesar Jamarun ${ }^{1 *}$, Syukri Arief $^{1}$, Hermansyah Aziz $^{1}$, Denny Akbar \\ Tanjung ${ }^{1,3}$, and Boy Isfa ${ }^{1}$ \\ ${ }^{1}$ Department of Chemistry, University of Andalas, Limau Manis, Padang 25163, West Sumatera, Indonesia \\ ${ }^{2}$ Department of Chemistry, University of Sari Mutiara Indonesia, Medan 20123, North Sumatera, Indonesia \\ ${ }^{3}$ Department of Agrotechnology, University of Medan Area, Medan 20223, North Sumatera, Indonesia
}

\section{*Corresponding author:}

email: novesarjamarun@sci.unand.ac.id

Received: September 3, 2021

Accepted: November 1, 2021

DOI: $10.22146 /$ ijc. 68888

\begin{abstract}
This study investigates the improvement of the mechanical, thermal, and morphological properties of linear low-density polyethylene (LLDPE)/cyclic natural rubber (CNR) after the addition of organo-precipitated calcium carbonate (O-PCC). The impact on the properties of the LLDPE/CNR/LLDPE-g-OA/O-PCC composites was investigated by a series of empirical experiments. First, the polymer composite was blended in the molten state using an internal mixer with a heating temperature of $160{ }^{\circ} \mathrm{C}$ and a rotation speed of $100 \mathrm{rpm}$. The LLDPE was placed in a chamber of internal mixer until melted, followed by CNR, LLDPE-g-OA, and O-PCC. The polymer composites with an O-PCC concentration of 5\% obtained the optimal mechanical properties compared to other variations, with a tensile strength of $17.17 \mathrm{MPa}$ and Young's modulus of 252.68 MPa. The presence of O-PCC resulted in better thermal stability and a change in the melting point temperature of $124^{\circ} \mathrm{C}$. The FTIR spectra of the polymer composite showed the specific characteristics of O-PCC at $872.1 \mathrm{~cm}^{-1}$. The morphology of the polymer composite indicates that the O-PCC is evenly dispersed in the polymer composite.
\end{abstract}

Keywords: O-PCC; LLDPE; CNR; LLDPE-g-OA; filler

\section{- INTRODUCTION}

Increasing awareness of the environment encourages both researchers and manufacturers to create environmentally-friendly products. For example, cyclic natural rubber $(\mathrm{CNR})$ is a natural rubber derivative in the form of a granular solid and is known as resiprene-35 (CAS Reg. no: 68441-13-4). CNR is an environmentallyfriendly and non-volatile resin used as a coating or paint binder on glass, metal, paper, and wood surfaces [1]. However, the application of CNR on the surface of polyolefin substrates, such as Linear Low-Density Polyethylene (LLDPE), is not suitable since LLDPE is semi-crystalline and has low surface energy [2]. Therefore, there is an opportunity to develop LLDPE/CNR-based polymer blend products and then be used as a reference in developing CNR as a paint binder for polyolefin surfaces, especially LLDPE.
The compatibility of polymer blends between polyolefin and CNR can be improved by the presence of a compatibilizer or coupling agent from one of the parts of the polymer blends. Mahendra et al. [3] reported the improvement of polymer blends between polypropylene (PP) and CNR using PP-g-MA and CNR-g-MA as compatibilizers. The oleic acid-grafted linear lowdensity polyethylene (LLDPE-g-OA) can also be used as compatibilizers to reduce the interfacial tension between the two polymer phases by increasing the interfacial adhesion of the two phases.

The presence of fillers in the polymer blends is needed to improve its mechanical and thermal properties. Pang et al. [4] mentioned that using kenaf fibers filler treated with amino acid lysine improved the mechanical, thermal, and morphological properties of LLDPE/PVOH/kenaf composites. Moreover, the 
chemical treatment of kenaf fibers using hydrated chromium(III) sulfate $\left(\left[\mathrm{Cr}\left(\mathrm{H}_{2} \mathrm{O}\right)_{6}\right]_{2}\left(\mathrm{SO}_{4}\right)_{3} \cdot 6\left(\mathrm{H}_{2} \mathrm{O}\right)\right)$ can also improve the mechanical, thermal, and morphological properties of LLDPE/PVOH/kenaf composites [5]. The use of precipitated calcium carbonate (PCC) as a filler in polymer materials has been widely developing because it includes natural materials that are abundant and easy to obtain [6-10]. PCC is calcite with an amorphous crystal structure and low hardness [11-13]. The addition of PCC in the polyolefin matrix improved the mechanical and physical properties of the composite in several ways: increased thermal conductivity, stiffness, dimensional stability, reduced injection molding cycle time, lowered shrinkage, relaxation of internal stresses, and increased anti-blocking [14].

Furthermore, the particle size in the nanometer scale makes this filler more easily dispersed than the micro or ordinary scale [15]. According to Zapata et al. [7], it is necessary to modify $\mathrm{CaCO}_{3}$ with oleic acid (OA) as a surfactant to obtain $\mathrm{O}-\mathrm{CaCO}_{3}$, which is more hydrophobic on the surface, so that the $\mathrm{O}-\mathrm{CaCO}_{3}$ can be evenly dispersed with no agglomeration on the composite. The $\mathrm{O}-\mathrm{CaCO}_{3}$ does not only function as fillers but also as a co-compatibilizer in non-polar polymer composites. de Oliveira et al. [16] reported that PCC in HDPE/PLA blends in the presence of a PE-g-MA compatibilizer and has shown the role of PCC as a cocompatibility since it can adsorb one of the blends. This study investigates the improvement of the mechanical, thermal, and morphological properties of organoprecipitated calcium carbonate (O-PCC) filled LLDPE/CNR composites with the presence of LLDPE-gOA compatibilizer.

\section{- EXPERIMENTAL SECTION}

\section{Materials}

Linear low-density polyethylene (LLDPE) Asrene UF-1810 with a density of $0.918 \mathrm{~g} / \mathrm{cm}^{3}$ and melt flow index (MFI) of $1.0 \mathrm{~g} / 10 \mathrm{~min}\left(190^{\circ} \mathrm{C} / 2.16 \mathrm{~kg}\right)$ was supplied by PT. Chandra Asri Petrochemical Tbk. (Jakarta, Indonesia). Cyclic natural rubber (CNR) Resiprene-35 with a density of $0.91 \mathrm{~g} / \mathrm{mL}$ and MFI of $36.37 \mathrm{~g} / 10 \mathrm{~min}$ $\left(190{ }^{\circ} \mathrm{C} / 2.16 \mathrm{~kg}\right)$ was obtained from PT. Industri Karet Nusantara (Deli Serdang, Indonesia). Precipitated calcium carbonate (PCC) Schaefer Precarb 100 with a density of $0.0027-0.00295 \mathrm{~g} / \mathrm{cm}^{3}$ was supplied by Schaefer Kalk (Kuala Lumpur, Malaysia). Oleic acid (OA) with a density of $0.895 \mathrm{~g} / \mathrm{mL}$ was obtained from Subur Kimia Jaya Chemical Company (Bandung, Indonesia). Benzoyl peroxide, xylene, ethanol, acetone, and methanol were obtained from Merck (Darmstadt, Germany). Oleic acid-grafted linear low-density polyethylene (LLDPE-g-OA) was prepared based on the methods conducted in prior work [17-18].

\section{Instrumentation}

The PCC and O-PCC nanoparticles' crystallite size was analyzed using an X-ray diffractometer (Shimadzu 6100). The mechanical properties (i.e., tensile strength, elongation at break, and Young's modulus) on polymer composites were determined using the Ultimate Testing Machine (GoTech AI-7000) with a maximum load cell capacity of $20 \mathrm{KN}$ at a speed of $10 \mathrm{~mm} / \mathrm{min}$. The test specimen was according to ASTM D638-14 (type I). The stability and thermal properties of the polymer composites were analyzed using the TGA/DTA (Hitachi STA-7300), with a heating rate of $10{ }^{\circ} \mathrm{C} / \mathrm{min}$ and a temperature range of 30 to $600{ }^{\circ} \mathrm{C}$. The functional groups of the PCC, O-PCC, OA, and polymer composites were analyzed using an FTIR spectrometer (Agilent Cary 630) at the wavenumbers of 650-4000 $\mathrm{cm}^{-1}$. The morphologies of the polymer composites were observed on the surface structure using a Scanning Electron Microscope (ZEISS EVO@MA10).

\section{Procedure}

\section{Organic modification of precipitated calcium carbonate (O-PCC)}

One $\mathrm{mL}$ of oleic acid $(\mathrm{OA})$ was added into a beaker glass containing $100 \mathrm{~mL}$ of $n$-hexane and then stirred. One gram of PCC was added into the solution during stirring and then heated at $60^{\circ} \mathrm{C}$ for $6 \mathrm{~h}$. The blends were filtered, washed with ethanol, and dried at $100{ }^{\circ} \mathrm{C}$ for 24 $\mathrm{h}$. The obtained results were in the form of O-PCC powder [7]. 


\section{Preparation composites \\ of LLDPE/CNR/LLDPE-g-OA/O-PCC}

The LLDPE pellets were slowly placed into a chamber on the internal mixer (Thermo HAAKE Polydrive) at $160{ }^{\circ} \mathrm{C}$ with a rotation speed of $100 \mathrm{rpm}$ for 5 min. After the LLDPE melted, CNR was added into the chamber, followed by LLDPE-g-OA as a compatibilizer in the polymer blend. It was then stirred and left for $5 \mathrm{~min}$. Next, the O-PCC was added into the polymer blends according to the variations in Table 1 and left for $10 \mathrm{~min}$ until the blending process was finished. The composites were then removed from the internal mixer, left at room temperature, and cut into small pieces $[3,19]$. The results obtained were LLDPE/CNR/LLDPE-g-OA/O-PCC composites. The same treatment of neat PCC was required for result comparison. Henceforth, LLDPE/CNR/LLDPE-g-OA blends were referred to as LCC, LLDPE/CNR/ LLDPE-g-OA/O-PCC composites as LCCO, and LLDPE/CNR/LLDPE-g-OA/PCC composites as LCCP.

\section{- RESULTS AND DISCUSSION}

\section{X-Ray Diffraction Analysis}

The XRD analysis was carried out on PCC and OPCC nanofillers to identify crystallite size and crystalline phase of filler. The XRD patterns obtained from PCC and O-PCC nanofillers are presented in Fig. 1. The characteristic peaks of PCC are at $2 \theta$ of $23.09^{\circ}, 29.46^{\circ}$, $35.97^{\circ}, 39.43^{\circ}, 43.16^{\circ}, 47.60^{\circ}, 48.55^{\circ}, 57.35^{\circ}, 60.64^{\circ}$, and $64.68^{\circ}$, corresponding to the $\mathrm{CaCO}_{3}$ phase, indicating the presence of $\mathrm{CaCO}_{3}$ in the PCC filler with a crystal size of $44.00 \mathrm{~nm}$ and a degree of crystallinity of $60.49 \%$. The characteristic peaks of O-PCC are at $2 \theta$ of $23.40^{\circ}$, $29.76^{\circ}, 36.27^{\circ}, 39.71^{\circ}, 43.46^{\circ}, 47.88^{\circ}, 48.83^{\circ}, 57.63^{\circ}$, $60.91^{\circ}$, and $64.84^{\circ}$ also attributable to the $\mathrm{CaCO}_{3}$ phase, which indicates the presence of $\mathrm{CaCO}_{3}$ in the O-PCC filler with a crystal size of $48.47 \mathrm{~nm}$ and a degree of crystallinity of $61.48 \%[12,20]$. Organic modification of PCC with OA caused a slight shift in the characteristic peaks of $\mathrm{CaCO}_{3}$ and a decrease in intensity. The presence of oleic compounds on the PCC surface caused an increase in the PCC crystallite size of $10.16 \%$ and crystallinity degree of $1.65 \%$.

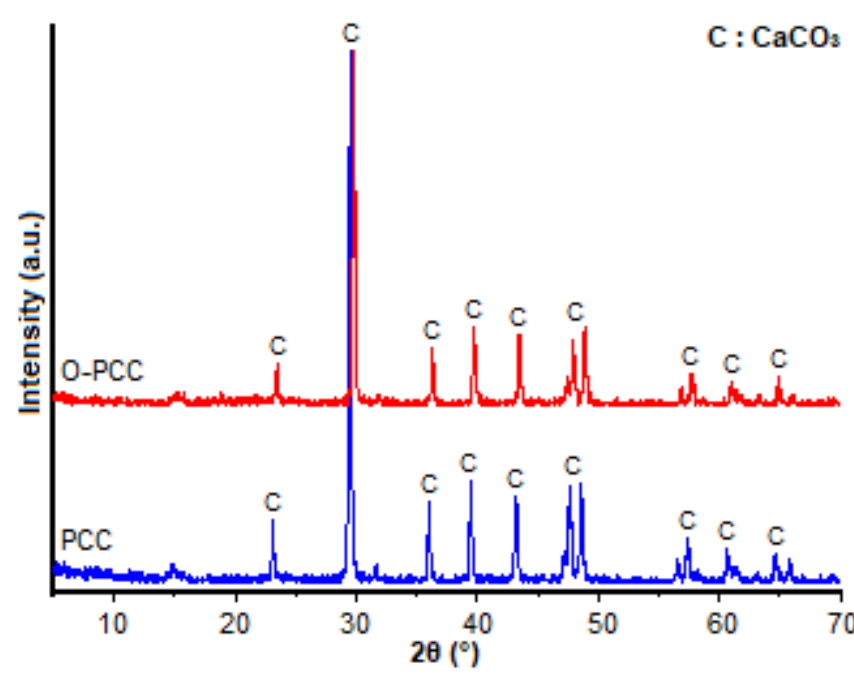

Fig 1. X-ray diffraction analysis of nanofillers

Table 1. Composition of polymer composites

\begin{tabular}{lccccc}
\hline $\begin{array}{l}\text { Sample } \\
\text { code }\end{array}$ & $\begin{array}{c}\text { LLDPE } \\
(\text { wt. } \%)\end{array}$ & $\begin{array}{c}\text { CNR } \\
(\text { wt.\% })\end{array}$ & $\begin{array}{c}\text { LLDPE-g-OA } \\
(\text { wt.\%) }\end{array}$ & $\begin{array}{c}\text { O-PCC } \\
\text { (wt.\%) }\end{array}$ & $\begin{array}{c}\text { PCC } \\
\text { (wt.\%) }\end{array}$ \\
\hline LCC & 67.5 & 27.5 & 5.0 & - & - \\
LCCO-1 & 67.0 & 27.0 & 5.0 & 1.0 & - \\
LCCO-2 & 66.5 & 26.5 & 5.0 & 2.0 & - \\
LCCO-3 & 66.0 & 26.0 & 5.0 & 3.0 & - \\
LCCO-4 & 65.5 & 25.5 & 5.0 & 4.0 & - \\
LCCO-5 & 65.0 & 25.0 & 5.0 & 5.0 & - \\
LCCP-1 & 67.0 & 27.0 & 5.0 & - & 1.0 \\
LCCP-2 & 66.5 & 26.5 & 5.0 & - & 2.0 \\
LCCP-3 & 66.0 & 26.0 & 5.0 & - & 3.0 \\
LCCP-4 & 65.5 & 25.5 & 5.0 & - & 4.0 \\
LCCP-5 & 65.0 & 25.0 & 5.0 & - & 5.0 \\
\hline
\end{tabular}




\section{Mechanical Properties}

The mechanical properties of the composites, including tensile strength, elongation at break, and Young's modulus, are shown in Fig. 2. Compared to the LCC blends, the LCCO composites showed better mechanical properties (higher tensile strength and Young's modulus) and decreased elongation at break. The improvement in mechanical properties was caused by the addition of O-PCC concentration into the LCCO composite. These results can be associated with the even dispersion quality of the fillers in the composite matrix and the potential interaction between the coupling agent and the polymer. The strong interfacial adhesion between the O-PCC particles with the polymer composites matrix macromolecular chains through the compatibilizer, and coupling agent resulted in load sharing and effective stress transfer on the interfacial zone between LLDPE/CNR with O-PCC [4-5,21]. In the LCCP composites, PCC addition did not significantly improve the mechanical properties because the unmodified PCC had poor dispersion quality and formed agglomerations when fillers were added continuously. In addition, the weak interfacial adhesion between the fillers and polymer composites matrix limited the load transfer, causing the material to be damaged due to particle de-cohesion and the formation of cavities around the fillers [21].

The value of Young's modulus on LCCO composites also showed a significant increase with the addition concentration of the O-PCC filler. The improvement in stiffness is associated with the strong interfacial adhesion between the filler and the compatible material and between the polymer and the compatible material [21]. The presence of O-PCC in polymer composites acts as fillers and as cocompatibilizers [7]. Meanwhile, there was no significant increase in LCCP composites due to the potential agglomeration and the cavities around the fillers [21]. The elongation at the break of the LCCO and LCCP composites shows a decrease along with the addition in fillers concentration. This decrease is related to the ductile
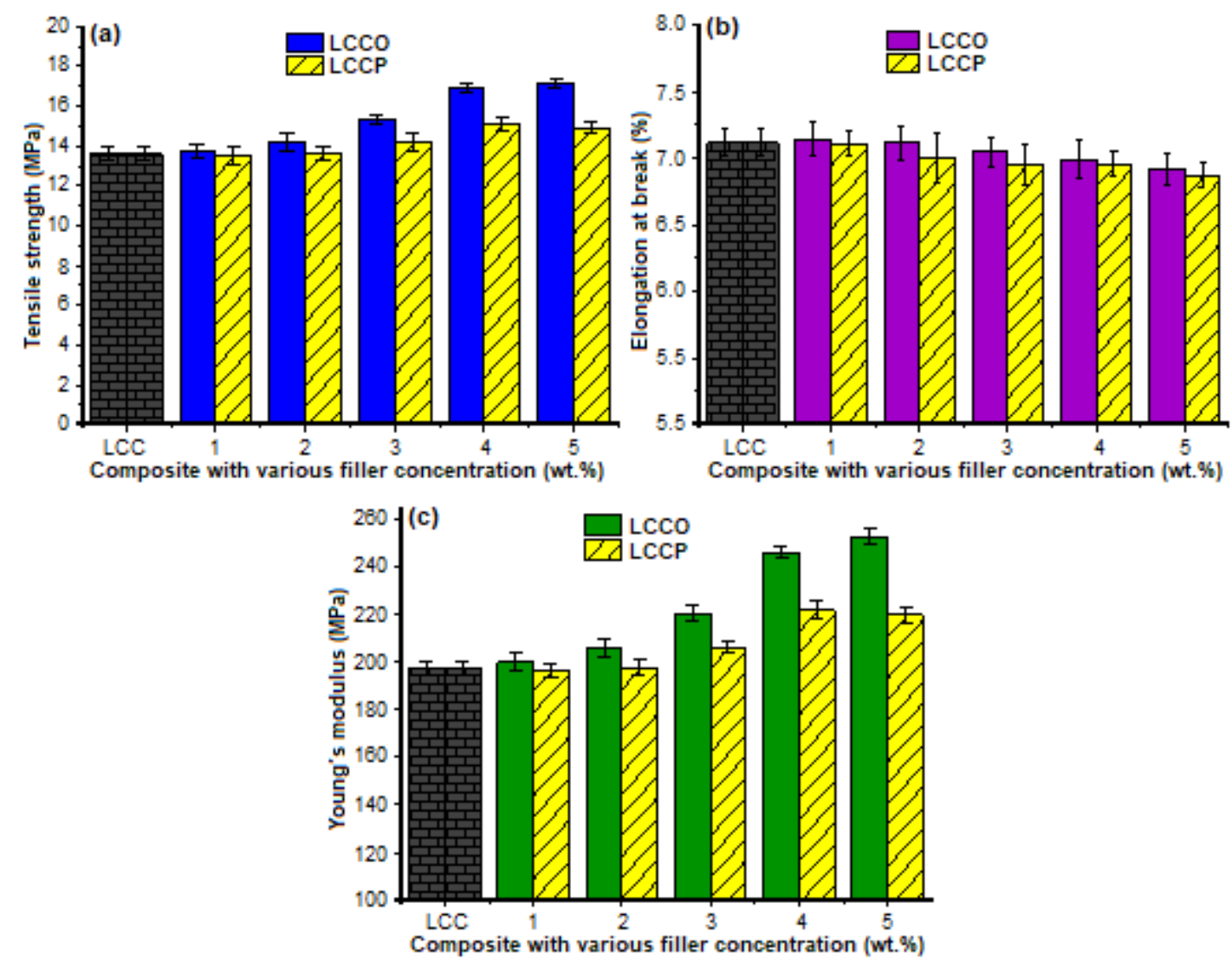

Fig 2. Tensile strength, elongation at break, and Young's modulus of polymer composites 
to brittle transition in the behavior of the polymer composites [21]. The increase in interfacial adhesion causes a decrease in the flexibility of the polymer composite [5].

\section{Thermal Analysis}

Based on the TGA (Fig. 3(a)) and DTG (Fig. 3(b)) curves, the initial degradation temperature at a $5 \%$ weight loss and the maximum degradation temperature of the polymer composite were represented by $\mathrm{T}_{5 \%}$ and $\mathrm{T}_{\max }$, respectively. The existence of fillers has increased the initial degradation temperature of both LCCO and LCCP, which can be seen at $\mathrm{T}_{5 \%}$. In addition, the presence of inorganic materials in the polymer composites with a certain amount has also increased the degradation temperature since PCC decomposes at high temperatures.

Meanwhile, LCC blends started to degrade at the temperature of $319{ }^{\circ} \mathrm{C}$. The thermal stability of the polymer composites increased after the addition of inorganic materials. The maximum degradation temperature of LCCO composites is higher than LCCP and LCC. These results illustrate that polymer composites treated with O-PCC fillers have higher thermal stability due to the increased interfacial adhesion between the polymer composite matrix and O-PCC fillers. Therefore, the addition of the modified PCC fillers increased the thermal stability of the LCCO composite [4-5].

$T_{m}$ and $T_{d}$ respectively represented the melting point temperature and the decomposition temperature of the polymer composite. The decomposition temperature of all samples showed endothermic peak phenomena (Fig. 3(c)) and did not show any significant difference at $\mathrm{T}_{\max }$ of the TGA curve. The first endothermic peak indicates the melting point temperature of each sample. The LCCO and LCCP composites showed a $\mathrm{T}_{\mathrm{m}}$ of $124{ }^{\circ} \mathrm{C}$. The LCC blends showed a $\mathrm{T}_{\mathrm{m}}$ of $123^{\circ} \mathrm{C}$, which indicates that the addition of OPCC/PCC fillers resulted in a higher $\mathrm{T}_{\mathrm{m}}$ than those without fillers. All samples are semi-crystalline because endothermic peaks have formed, and no transitions occur before the $T_{m}$ [18]. Data analysis of the TGA and DTG curves is summarized in Table 2.

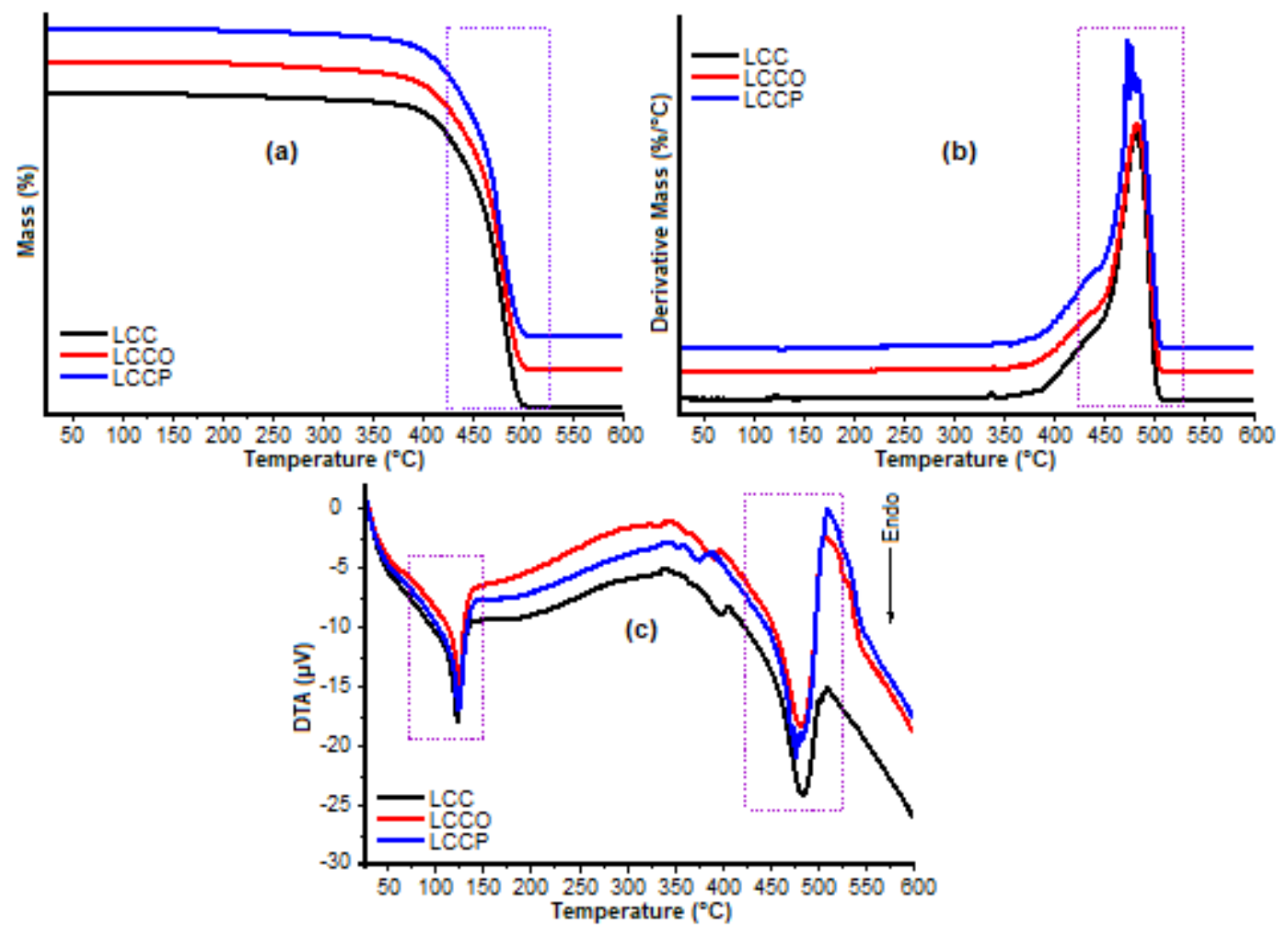

Fig 3. (a) TGA, (b) DTG, (c) DTA curves of the polymer composites 
Table 2. Thermal analysis data of LCC, LCCO, and LCCP

\begin{tabular}{lcccc}
\hline Sample & $\begin{array}{c}\mathrm{T}_{5 \%} \\
\left({ }^{\circ} \mathrm{C}\right)\end{array}$ & $\begin{array}{c}\mathrm{T}_{\max } \\
\left({ }^{\circ} \mathrm{C}\right)\end{array}$ & $\begin{array}{c}\mathrm{T}_{\mathrm{m}} \\
\left({ }^{\circ} \mathrm{C}\right)\end{array}$ & $\begin{array}{c}\mathrm{T}_{\mathrm{d}} \\
\left({ }^{\circ} \mathrm{C}\right)\end{array}$ \\
\hline LCC & 319 & 480 & 123 & 480 \\
LCCO & 382 & 481 & 124 & 481 \\
LCCP & 389 & 471 & 124 & 476 \\
\hline
\end{tabular}

\section{FTIR Analysis}

The FTIR spectra of OA, PCC, and O-PCC are presented in Fig. 4(a). The absorption at 2922.2-2855.1 $\mathrm{cm}^{-1}$ indicates stretching vibrations of methyl and methylene groups of oleic acid, suggesting that it has been adsorbed on the PCC surface. The band at $1701.1 \mathrm{~cm}^{-1}$ indicates the presence of carbonyl $(\mathrm{C}=\mathrm{O})$ stretching vibrations of $\mathrm{CaCO}_{3}$. A strong band at $1394.0 \mathrm{~cm}^{-1}$ indicates carbonate stretching vibrations. The absorptions at 872.1 and $723.1 \mathrm{~cm}^{-1}$ correspond to the typical vibrational bands of calcite [7].

The FTIR spectra of the LCC, LCCO, and LCCP are presented in Fig. 4(b). The band at $2914.7-2847.6 \mathrm{~cm}^{-1}$ indicates stretching vibrations in methyl and methylene from organic polymer compounds. The bands at 1461.1 and $1371.6 \mathrm{~cm}^{-1}$ indicate the presence of $-\mathrm{CH}_{2}$ and $-\mathrm{CH}_{3}$ bending vibrations. An absorption at $723.1 \mathrm{~cm}^{-1}$ indicates the stretching vibrations of $\mathrm{C}-\mathrm{H}[4-5,22]$. The small band at $1654.9 \mathrm{~cm}^{-1}$, which shows $\mathrm{C}=\mathrm{C}$ double bond originating from the CNR, is visible in the LCC spectrum but not in the LCCO and LCCP since it is possibly overlapped with the absorption at $1701.1 \mathrm{~cm}^{-1}$ at the same intensity, which indicates the presence of oleic groups on the surface of the O-PCC. In LCCP composites, the absorption intensity at $1701.1 \mathrm{~cm}^{-1}$ appears to be reduced due to the absence of oleic groups on the PCC surface. The difference in the spectrum of LCCO and LCCP is observed from the absorption at $872.1 \mathrm{~cm}^{-1}$, where the intensity of O-PCC is found to be weaker than PCC $[7,18,21]$.

\section{Morphological Analysis}

Analysis of surface morphology of the composites was carried out to observe the surface structure of LCC, LCCO, and LCCP (see Fig. 5). The surface morphology of LCC shows a slightly rough surface structure and appears to achieve homogeneous blends. LCCO composites show a surface structure that is not much different from LCC, where a surface structure is slightly rough and seems to have homogeneous composites because the O-PCC was evenly distributed on the surface of the polymer composites. LCCP shows a rough surface structure and appears non-homogeneous composites because PCC is not unevenly dispersed or agglomerates on the surface of the polymer composites. PCC has modified with oleic acid and clearly showed its role as a dispersing agent in LCCO composites, which causes the surface structure of the LCCO not to be significantly different from the LCC blends since the O-PCC was evenly
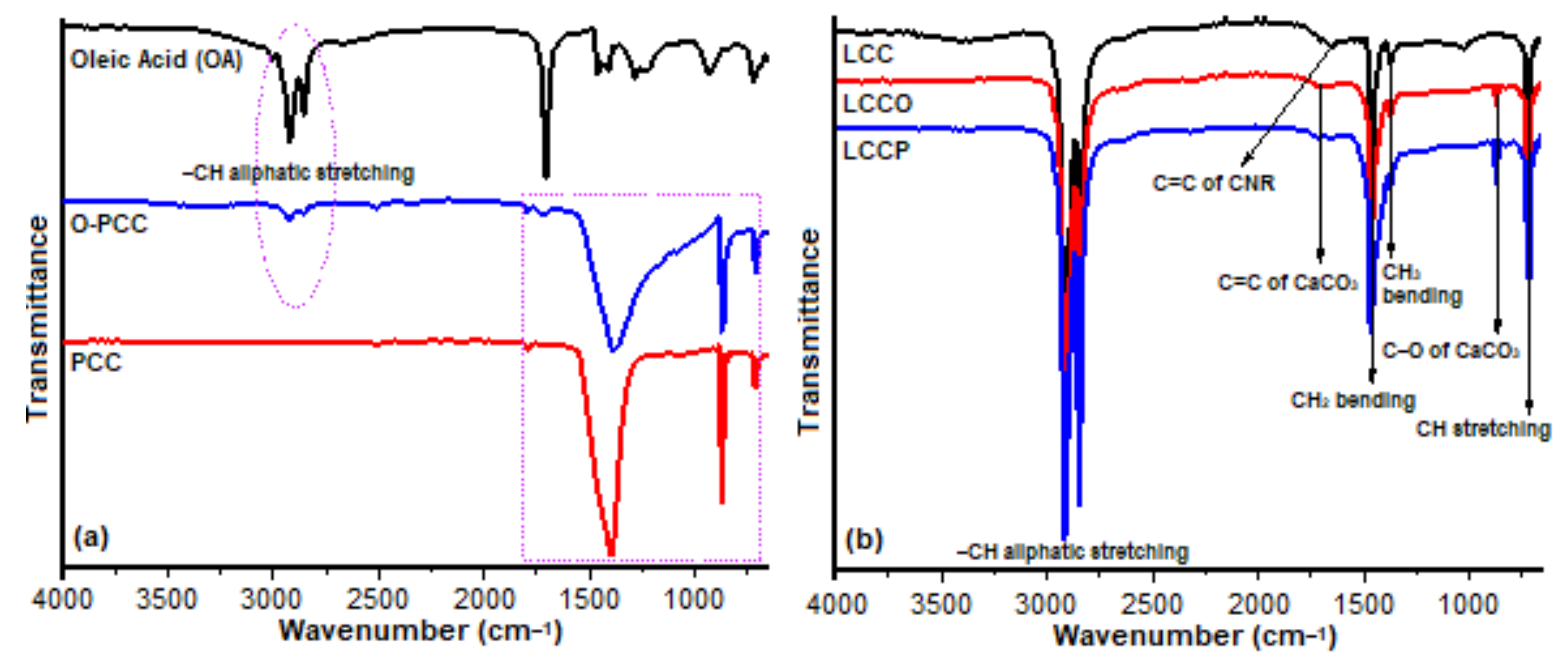

Fig 4. FTIR spectra of (a) nanofillers, (b) polymer composites 


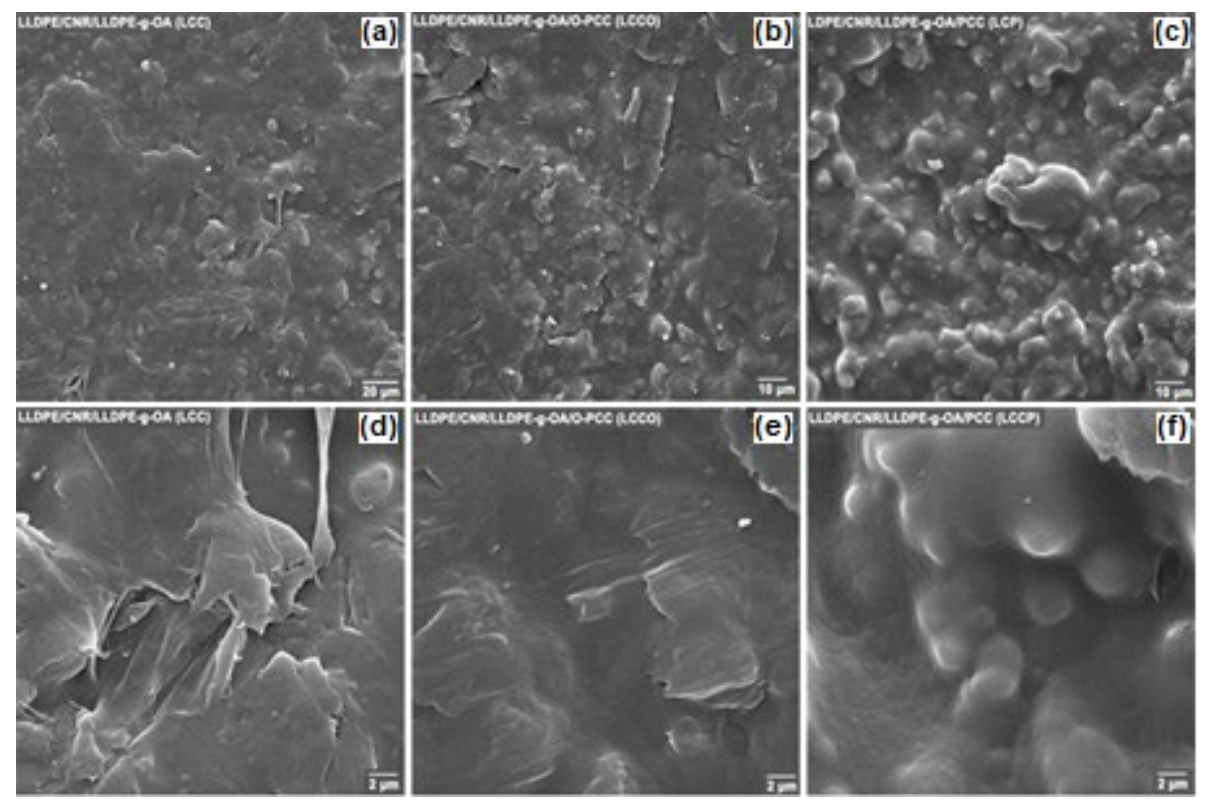

Fig 5. SEM micrographs of (a) LCC, (b) LCCO, (c) LCCP at 1000× magnification, and (d) LCC, (e) LCCO, (f) LCCP at $5000 \times$ magnification

dispersed on the LCCO composite. The presence of OPCC is not only a filler but also acts as a co-compatibilizer that makes the composite more compatible with the ingredients [7].

\section{- CONCLUSION}

The presence of O-PCC nanoparticles (crystal size of $48.4 \mathrm{~nm}$ and crystallinity of $61.48 \%$ ) as a filler has affected the mechanical properties of the LCCO composites. An O-PCC concentration of $5 \%$ has resulted in tensile strength of $17.17 \mathrm{MPa}$, increasing $26.2 \%$ compared to the unfilled LCC blends. The Young's modulus was $252.68 \mathrm{MPa}$, about $28.1 \%$ higher than the unfilled one. The presence of O-PCC in LCCO composites has achieved better thermal stability than LCC blends and LCCP composites, with a maximum mass degradation temperature of $481{ }^{\circ} \mathrm{C}$. The FTIR spectra of LCCO composites showed the characteristic absorption of $\mathrm{CaCO}_{3}$ at 872.1 and $1701.1 \mathrm{~cm}^{-1}$, indicating the presence of O-PCC in LCCO composites. The morphology of the LCCO composite resulted in a slightly rough and homogeneous surface structure with the homogenously dispersed O-PCC in the composite.

\section{- ACKNOWLEDGEMENTS}

The author would like to thank the Ministry of Education, Culture, Research, and Technology of the Republic of Indonesia for the BPPDN scholarship program and funding for doctoral dissertation research grants in 2021, with the main contract number is 104/ E4.1/AK.04.PT/2021 and derivative contract number is contract/6.17/PT.01.03/PDD-Material Maju/2021.

\section{- AUTHOR CONTRIBUTIONS}

AHR conducted the experiment. AHR, DAT, and $\mathrm{BI}$ conducted the calculations and analysis. AHR wrote the manuscript. NJ, SA, HA, and AHR revised the manuscript. All authors agreed to the final version of this manuscript.

\section{- REFERENCES}

[1] Aritonang, B., Tamrin, T., Wirjosentono, B., and Eddiyanto, E., 2019, Grafting of oleic acid on cyclic natural rubber resiprene-35 using dicumyl peroxide initiator and divinylbenzene compatibilizers for paint binder in polyamide thermoplastics, Orient. J. Chem., 35 (1), 173-179. 
[2] Rahayu, I., Zainuddin, A., and Hendrana, S., 2020, Improved maleic anhydride grafting to linear low density polyethylene by microencapsulation method, Indones. J. Chem., 20 (5), 1110-1118.

[3] Mahendra, I.P., Wirjosentono, B., Tamrin, T., Ismail, H., Mendez, J.A., and Causin, V., 2019, The influence of maleic anhydride-grafted polymers as compatibilizer on the properties of polypropylene and cyclic natural rubber blends, J. Polym. Res., 26 (9), 215.

[4] Pang, A.L., Ismail, H., and Abu Bakar, A., 2020, Effect of lysine treatment on the properties of linear lowdensity polyethylene/poly(vinyl alcohol)/kenaf composites, BioResources, 15 (1), 1915-1926.

[5] Pang, A.L., Ismail, H., and Abu Bakar, A., 2018, Mechanical, morphological, and thermal properties of kenaf filled linear low-density polyethylene/ poly(vinyl alcohol) composites: Effect of chemical treatment, J. Vinyl Addit. Technol., 24, E164-E171.

[6] Fernando, N.A.S., and Thomas, N.L., 2012, Investigation of precipitated calcium carbonate as a processing aid and impact modifier in poly(vinyl chloride), Polym. Eng. Sci., 52 (11), 2369-2374.

[7] Zapata, P.A., Palza, H., Díaz, B., Armijo, A., Sepúlveda, F., Ortiz, J.A., Ramírez, M.P., and Oyarzún, C., 2019, Effect of $\mathrm{CaCO}_{3}$ nanoparticles on the mechanical and photo-degradation properties of LDPE, Molecules, 24 (1), 126.

[8] Lourenço, A.F., Gamelas, J.A.F., and Ferreira, P.J., 2015, Precipitated calcium carbonate modified by the layer-by-layer deposition method-Its potential as papermaking filler, Chem. Eng. Res. Des., 104, 807813.

[9] Declet, A., Reyes, E., and Suárez, O.M., 2016, Calcium carbonate precipitation: A review of the carbonate crystallization process and applications in bioinspired composites, Rev. Adv. Mater. Sci., 44, 87107.

[10] Wardhani, S., Prasetia, F., Khunur, M.M., Purwonugroho, D., and Prananto, Y.P., 2018, Effect of $\mathrm{CO}_{2}$ flow rate and carbonation temperature in the synthesis of crystalline precipitated calcium carbonate (PCC) from limestone, Indones. J. Chem., 18 (4), 573-579.

[11] Piskin, S., and Dere Özdemir, O., 2012, Effect of process conditions on crystal structure of precipitated calcium carbonate $\left(\mathrm{CaCO}_{3}\right)$ from fly ash: $\mathrm{Na}_{2} \mathrm{CO}_{3}$ preparation conditions, Int. J. Biol. Ecol. Environ. Sci., 1 (6), 2277-4394.

[12] Erdogan, N., and Eken, H.A., 2017, Precipitated calcium carbonate production, synthesis and properties, Physicochem. Probl. Miner. Process., 53 (1), 57-68.

[13] Sisca, V., Deska, A., Syukri, S., Zilfa, Z., and Jamarun, N., 2021, Synthesis and characterization of $\mathrm{CaO}$ limestone from Lintau Buo supported by $\mathrm{TiO}_{2}$ as a heterogeneous catalyst in the production of biodiesel, Indones. J. Chem., 21 (4), 979-989.

[14] Lin, Y., and Chan, C.M., 2012, "Calcium Carbonate Nanocomposites" in Advances in Polymer Nanocomposites, Woodhead Publishing, Cambridge, UK, 55-90.

[15] Ouarhim, W., Semlali Aouragh Hassani, F.Z., Bouhfid, R., Thomas, S., Sarathchandran, C., and Chandran, N., 2020, "Rheology of Polymer Nanocomposites" in Rheology of Polymer Blends and Nanocomposites, Elsevier, Amsterdam, Netherlands, 73-96.

[16] de Oliveira, A.G., Moreno, J.F., de Sousa, A.M.F., Escócio, V.A., de Oliveira Cavalcanti Guimarães, M.J., and da Silva, A.L.N., 2019, Composites based on high-density polyethylene, polylactide and calcium carbonate: Effect of calcium carbonate nanoparticles as co-compatibilizers, Polym. Bull., 77 (6), 2889-2904.

[17] Liu, M., Liu, Z., Ding, S., Li, S., and Zhang, L., 2003, Graft copolymerization of oleic acid onto lowdensity polyethylene in the molten state, J. Appl. Polym. Sci., 90 (12), 3299-3304.

[18] Aritonang, B., Tamrin, T., Wirjosentono, B., and Eddiyanto, E., 2020, Effect of graft copolymerization of oleic acid on to cyclic natural rubber in polyamide, Case Stud. Therm. Eng., 21, 100690.

[19] dos Anjos, E.G.R., Backes, E.H., Marini, J., Pessan, 
L.A., Montagna, L.S., and Passador, F.R., 2019, Effect of LLDPE-g-MA on the rheological, thermal, mechanical properties and morphological characteristic of PA6/LLDPE blends, J. Polym. Res., 26 (6), 134.

[20] Sisca, V., Tanjung, D.A., Syukri, S., Zilfa, Z., and Jamarun, N., 2021, Catalytic activity of precipitated calcium carbonate for biodiesel production, Rasayan J. Chem., 14 (3), 1587-1593.

[21] Doufnoune, R., Haddaoui, N., and Riahi, F., 2008,
Effects of coupling agents on the tensile properties of calcium carbonate filled LDPE compatibilized with maleic anhydride-g-LDPE (Part I), Int. J. Polym. Mater. Polym. Biomater., 57 (4), 295-318.

[22] Pang, A.L., Ismail, H., and Bakar, A.A., 2018, Linear low density polyethylene/poly(vinyl alcohol)/kenaf composites: Effect of natural weathering on functional group, weight loss characteristics, tensile, morphological and thermal properties, Sains Malays., 47 (3), 571-580. 